\title{
A tragédia como gênero literário e a negação da "justiça poética" no terceiro livro de 0 mundo como vontade e representação, de Schopenhauer
}

\section{The tragedy as a literary genre and the denial of "poetic justice" in the third book of the World as Will and Representation, of Schopenhauer}

\author{
Eli Vagner Francisco Rodrigues \\ Professor da Universidade Estadual Paulista - UNESP \\ E-mail: elivagner@faac.unesp.br
}

\begin{abstract}
Resumo: O gênero literário da tragédia é apontado por Schopenhauer, no parágrafo 51 de $O$ mundo como vontade e representação, como a mais perfeita tradução da visão de mundo característica de sua filosofia. No capítulo citado, Schopenhauer faz uma crítica ao recurso literário denominado "Justiça poética", apontando-o como um recurso que subverteria completamente a essência deste gênero. Este artigo apresenta uma análise dos argumentos de Schopenhauer contra o uso do recurso da justiça poética, além de apresentar, em linhas gerais, as teses de Schopenhauer sobre o gênero da tragédia em relação à sua filosofia. Para Schopenhauer, o sentido verdadeiro da tragédia reside na profunda intelecção de que os heróis não expiam os erros cometidos na ação dramática, mas que pagam, com o fatalismo final característico do gênero, pelo próprio pecado original, isto é, a culpa pela própria existência.
\end{abstract}

Palavras-chave: Tragédia; Justiça Poética; Pecado Original.
Abstract: The literary genre of tragedy is pointed out by Schopenhauer, in Chapter 51 of The World as Will and Representation, as the most perfect worldview translation feature of his philosophy. Chapter quoted Schopenhauer criticizes the literary device called "poetic justice" pointing it as a resource that completely undermine the essence of this genre. This article presents an analysis of the arguments of Schopenhauer against using the feature of poetic justice, in addition to presenting, in general, the thesis of Schopenhauer on the genre of tragedy in relation to his philosophy. For Schopenhauer, the real tragedy meaning lies in the profound understanding that heroes do not atone for the mistakes made in the dramatic action, but they pay with the characteristic of the genre end fatalism, by itself original sin, that is, the blame for the very existence.

Keywords: Tragedy; Poetic Justice; Original Sin. 


\section{Introdução}

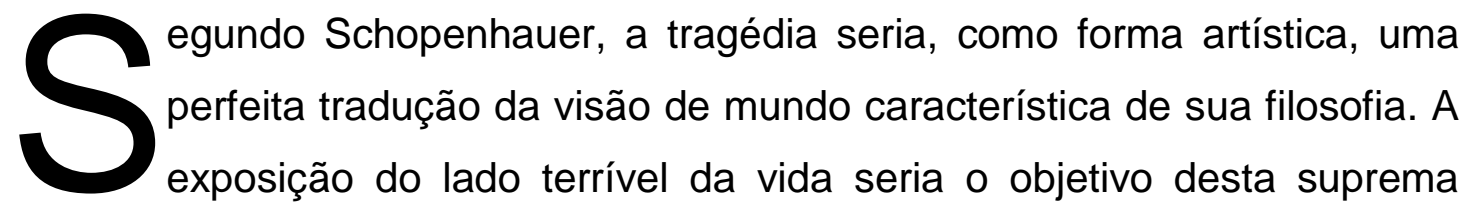
realização poética. Nos temas recorrentes das mais importantes e famosas tragédias encontramos, segundo o filósofo, um completo exemplo das dores do mundo, a saber, "o inominado sofrimento, a miséria humana, o triunfo da maldade, o império do cínico acaso, a queda inevitável do justo e do inocente"1. A partir dessas temáticas trágicas podemos encontrar, nesta suprema forma de arte, uma indicação significativa da essência do mundo e do ser. A tragédia representaria o próprio "conflito da Vontade consigo mesma" ${ }^{2}$ no seu grau mais elevado de objetidade. No capítulo 37 do Tomo II de $O$ mundo como vontade e representação denominado $A$ propósito da estética da poesia (Zur Äesthetik der Dichtkunst) e também nas lições sobre a Metafísica do Belo, Schopenhauer afirma que o prazer que a tragédia nos proporciona não pertence simplesmente ao sentimento de belo, mas ao próprio sentimento do sublime.

Nosso prazer na tragédia não pertence ao sentimento do belo, mas ao do sublime; sim é o grau mais elevado desse sentimento. Pois assim como pela visão do sublime na natureza desviamo-nos do interesse da vontade para nos comportarmos de maneira puramente contemplativa, assim também na catástrofe trágica desviamo-nos da Vontade de vida mesma ${ }^{3}$.

No que diz respeito às inúmeras variações que a literatura trágica apresenta ao longo da história da arte literária, Schopenhauer faz uma distinção interpretativa essencialmente ligada à metafísica e à sua interpretação moral do mundo. Para o filósofo, algumas tragédias representam a perfeita expressão da vida, outras não atingem este nível de significação e de expressão. Encontramos, também, tanto no livro terceiro de $O$ mundo como vontade e representação como nas lições sobre a Metafísica do Belo, um pequeno elenco de tragédias e alguns comentários que justificam as classificações relativas à maior ou menor perfeição das obras. Os comentários críticos de Schopenhauer nos permitem, com alguma liberdade,

1 SCHOPENHAUER, A. MVR I, § 51, p. 333.

2 Idem, ibidem.

3 SCHOPENHAUER, A. MB, cap. 16, p. 226.

A tragédia como gênero literário e a negação da "justiça poética" no terceiro livro de O mundo como vontade e representação, de Schopenhauer 
desenvolver um pequeno esboço de uma "teoria literária" da tragédia na obra do mestre de Frankfurt.

\section{A justiça poética (poetisch Gerechtkeit)}

Um aspecto que, a meu ver, merece uma nota é a consideração relativa ao conceito de "justiça poética" (poetisch Gerechtkeit) e a forma como este recurso se torna um critério para a classificação efetuada pelo filósofo. O conceito de justiça poética não é desenvolvido por Schopenhauer, como é, por exemplo, o de "justiça eterna" (ewige Gerechtigkeit) como uma consequência de sua concepção metafísica. Antes, o conceito é tomado da crítica literária europeia do século XVIII e citado sem maiores aprofundamentos no livro terceiro. Como veremos, no entanto, este conceito pode ser extremamente útil para a compreensão do lugar da tragédia no panteão das artes e de sua interpretação em relação à visão de mundo de Schopenhauer. No que diz respeito à crítica da tragédia, a interpretação de Samuel Johnson é citada como exemplo de "inépcia literária, crítica obtusa e ingenuidade", sobretudo com relação aos comentários dirigidos à obra de Shakespeare. Este último, segundo Samuel Johnson, não teria motivos dramáticos para culpar as "Ofélias, Desdêmonas e Cordélias" atribuindo a elas um destino trágico. Para Schopenhauer, veremos, este destino é plenamente justificado quando se considera a vida humana a partir de uma culpa primordial que acompanha a todos, visão que, segundo o filósofo, falta à perspectiva otimista racional-protestante que pode estar nos fundamentos da crítica de Johnson. As concepções de justiça que se colocam neste embate interpretativo são radicalmente diferentes. Schopenhauer argumenta que a introdução da justiça poética no universo da tragédia implica na perda do verdadeiro sentido do gênero literário em questão.

Mas qual seria, então, o significado de tal recurso dramático no contexto de um gênero literário caracterizado por más fortunas? A justiça poética seria um artifício de justificação ou compensação do sofrimento do herói trágico, que é introduzido na ação dramática de algumas tragédias. Segundo Leopoldo Bernucci, no artigo Justiça Poética na épica latino americana moderna ${ }^{4}$ o conceito foi

4 Cf. BERNUCCI, L. Justiça poética na épica latino americana moderna, p. 238-246.

A tragédia como gênero literário e a negação da "justiça poética" no terceiro livro de $\mathrm{O}$ mundo como vontade e representação, de Schopenhauer 
desenvolvido na crítica literária europeia durante o século XVII. Naquela época, segundo Bernucci, as discussões em torno da Poética de Aristóteles, mais precisamente sobre as ideias do filósofo sobre a tragédia, levaram o argumento ao campo da Moral e da Ética. No entanto, o próprio Aristóteles defende, e com razões absolutamente plausíveis, afirma Bernucci, que a noção de tragédia deixa de existir a partir do momento em que consideremos sanções para os maus e benefícios para os bons. Em outras palavras, o sentimento da tragédia exige que haja injustiça, e que esta, como tal, venha a coroar o desfecho da peça. Mais do que isso, é preciso, também, um sentimento de injustiça gerado por um motivo não explicitamente esclarecido para provocar uma reação de espanto e indignação com relação ao enredo. Este sentimento de indignação seria fundamental para desencadear uma reação catártica no público. A. C. Bradley, citado por Bernucci, ao estudar as tragédias de Shakespeare, proclama que a justiça poética introduziria um princípio segundo o qual a prosperidade e a adversidade seriam distribuídas em proporção aos méritos dos agentes e que, para ele, esta distribuição estaria em flagrante contradição com os fatos da vida, isto é, haveria um elemento de injustiça que não pode e não deve ser negado nos enredos trágicos. É possível que em todas as poéticas europeias do século XVII, comenta Bernucci, e, principalmente do XVIII, com exceção da de John Dryden, A Defence of an Essay of Dramatic Poetry (1668), estejam prescritas regras para se combater os vícios e premiar as virtudes. Bernucci conclui a este respeito:

$\mathrm{E}$, se as asserções de Bradley estiverem corretas, logo se deduz que na realidade do cotidiano, e Shakespeare pôde magistralmente captar essa visão como ninguém, a inversão na ordem dos castigos e gratificações é o que prevalece. Segundo esta mesma realidade, o vilão se salva enquanto o virtuoso é condenado ${ }^{5}$.

Assim como Schopenhauer, Bradley parece perceber que, para Shakespeare, não faz nenhum sentido o uso de um recurso literário que equilibre de alguma forma a injustiça essencial que deve ser característica de uma tragédia e que o destino trágico de personagens que possuem um caráter reto, uma ação justa durante o enredo, podem muito bem ocorrer e, mais do que isso, tal ocorrência reforça o caráter essencial de representação da vida. Bernucci aponta, ainda, que para a

5 BERNUCCI, L. Justiça poética na épica latino americana moderna, p. 238-246. 
crítica literária europeia do século XVIII, a justiça poética seria usada para inspirar um comportamento moral supostamente adequado no público, ilustrando, em algum aspecto, o triunfo do bem sobre o mal. Neste sentido, a justiça poética não se limitaria a ideia de exigir que o vício seja punido e a virtude recompensada, mas também exigiria o triunfo de uma noção de equilíbrio, mesmo nas peças com final caracterizado por forte fatalismo. Segundo esse princípio, a ação dramática deveria conter um apelo moral, ainda que em sua totalidade expressiva fosse trágica. $O$ que está em jogo aqui, no que diz respeito à arte e à moral é a possibilidade de ensinála. Com relação à arte especificamente, a questão é se a sua função seria representar o que a vida "realmente é", a ideia da arte como um espelho da vida, ou se ela deveria ser portadora de uma função educativa, pedagógico-moral. No século XX, a filósofa Martha C. Nussbaum publicou uma obra denominada Poetic Justice: The Literary Imagination and Public Life, na qual desenvolve a tese de que obras literárias, sobretudo obras do gênero romance realista podem influenciar, através da empatia e identificação com personagens (gênero, raça, classe) a consciência moral dos indivíduos e grupos sociais. A obra de Nussbaum, que não será examinada aqui, está fundamentada em outras bases conceituais que não as da teoria literária dos séculos XVII e XVIII e, portanto aparece em nosso texto apenas a título de rápida menção. Vale notar, pórem, como veremos a seguir, que a tese central possui alguma similaridade, sobretudo no aspecto da empatia com o público, com a motivação de certos autores do século XVIII mencionados por Bernucci em sua análise da crítica moderna. Esta motivação seria baseada na suposição de que o público em geral se identifica com os personagens bons e justos. O sofrimento do herói trágico, quando este é inocente, pelo menos aparentemente na ação dramática provoca a compaixão do público e a ação compensatória da justiça poética provocaria uma espécie de catárse. O público naturalmente deseja uma compensação para os bons e igualmente uma punição para os maus mesmo em enredos explicitamente trágicos. A justiça poética ofereceria contentamento para o público. Já se disse que esta tendência, em geral, quando ocorre no horizonte da arte, pode dar origem à passagem do status de arte para o de entretenimento e representa a própria refuncinalização da arte e mesmo um indício de sua decadência. Lembramos que o conceito de drama, que é disitnto da definição de 
tragédia, pode comportar uma justiça poética, pois este ao incorporar tanto a comédia como a farsa, o melodrama e elementos da própria tragédia, é mais abrangente em suas possibilidades. A tragédia, em si, seria mais restrita em suas possibildades. Sua função artísitica está muito mais delimitada enquanto representação do sofrimento humano. Neste sentido, a nosso ver, é que soa um tanto absurdo a introdução de um elemento de justiça, a fim de compensar uma virtude, na estrutura de uma obra trágica.

\section{Contradição entre justiça poética e pecado original}

Todas as justificativas para a introdução de uma justiça poética esbarram na concepção schopenhaueriana de tragédia. Em primeiro lugar, para Schopenhauer, não é possível formar um caráter ensinando uma moral ou mesmo frequentando aulas de ética. Além disso, soaria estranho para o filósofo defender um tipo de tragédia que não levasse à resignação e à negação da vontade por parte do herói trágico, ou mesmo à morte dos personagens centrais. Para o filósofo, a introdução da chamada "justiça poética", demonstra um desconhecimento total da essência da tragédia que é, por sua vez, desconhecimento da própria essência do mundo. Segundo Schopenhauer, a justiça poética seria resultado de uma visão rasa e otimista da vida. Ele associa esta concepção a uma espécie de racionalismo protestante que, por sua vez, teria origem na concepção de vida característica do judaísmo.

Por sua vez, a exigência da chamada justiça poética baseia-se sobre o desconhecimento total da essência da tragédia, em verdade desconhecimento do mundo. De maneira mais gritante percebe-se essa inépcia literária nas críticas obtusas, coerente com sua ingenuidade, que o doutor Samuel Johnson dirige às peças isoladas de Shakespeare, censurando a sua licenciosidade: qual fato levou as Ofélias, Desdêmonas, as Cordélias a serem culpáveis? -Só a visão de mundo rasa, racional protestante, ou melhor dizendo, judaica fará a exigência de justiça poética ${ }^{6}$. 
Schopenhauer não vê no judaísmo uma interpretação autêntica e verdadeira da existência. Segundo o filósofo, somente o que concilia sua filosofia com o Antigo Testamento é a história do pecado original. O mito do pecado original seria a única verdade metafísica que se pode encontrar no livro sagrado dos judeus. Mas em que consiste o mito do pecado original? Segundo o filósofo o mito indica que o mundo é obra de nossa própria culpa, e que, como algo originário da vontade seria melhor não existir. Neste sentido, a culpa pela origem do mundo, e de nossa própria origem, repousa sobre nós mesmos. Em primeiro lugar, se a nossa própria existência é concebida assim (pecaminosa, decaída, em dívida) a introdução do recurso dramático da justiça poética não pode fazer nenhum sentido e, por isso mesmo, desclassifica as obras e os autores que lançam mão deste artifício de "lógica dramática" em relação àquelas obras nas quais o herói paga, com o seu sofrimento, não somente por algum ato que cometeu no decorrer da estória contada, mas pelo pecado originário de nascer. O resultado da introdução da justiça poética, portanto, seria uma falsificação da obra de arte, uma banalização de sua função essencial, uma descaracterização de um produto exemplar da cultura humana.

Schopenhauer aprofunda um pouco mais esta discussão através de uma classificação mais específica desenvolvida no parágrafo 51 de 0 mundo como vontade e representação. Esta classificação se refere aos recursos estruturais usados pelos autores de obras trágicas no processo criativo e não se refere somente ao recurso da justiça poética. O filósofo divide em três tipos, ou possibilidades de elaboração de uma obra desta natureza. No primeiro, a tragédia, o evento trágico, pode ocorrer em primeiro lugar, mediante uma maldade extraordinária, em segundo lugar, pode ocorrer mediante o destino cego, acaso ou erro, e, por fim, pode ocorrer pela mera disposição mútua das pessoas e combinação de suas relações recíprocas de modo que não seria preciso um "erro monstruoso nem um acaso inaudito, nem um caráter malvado acima de toda medida e que atinge os limites da perversidade humana"7, mas apenas a mera relação entre os caracteres de modo que não se pode atribuir a autoria do ato de injustiça a nenhum dos lados. Segundo Schopenhauer, este último tipo de tragédia supera em muito as demais. E, podemos acrescentar, este tipo supera os demais justamente por não caber neste caso

7 Idem, p. 335.

A tragédia como gênero literário e a negação da "justiça poética" no terceiro livro de O mundo como vontade e representação, de Schopenhauer 
nenhum apelo à justiça poética. Ora se o simples fato de manifestar nosso caráter nas relações humanas nos leva a um destino trágico não há necessidade de justificação do sofrimento no final, justamente pela culpa repousar exatamente em nosso próprio caráter. Neste sentido, Schopenhauer propõe que a grande infelicidade na tragédia deve ser mostrada não como exceção, não como algo produzido por circunstâncias raras, mas como algo que provém das ações espontâneas dos caracteres humanos, pois é aí que reside o foco de onde será gerada a "justificativa" para o evento trágico. Ademais, complementa, "nos outros casos temos a chance da renúncia e ao afastamento da origem do mal" ${ }^{8}$. No caso em que nós mesmos causamos ou somos a origem do mal, que está em nós, não teríamos o direito de denunciar ou exigir qualquer justiça. Continuando sua análise Schopenhauer acrescenta um comentário que demonstra a profundidade de suas apreciações sobre arte. O filósofo ressalta que ao mesmo tempo em que é mais significativo este tipo de tragédia destacado é, consequentemente, mais difícil de produzi-lo, pois, para elaborá-lo, precisamos criar o maior efeito dramático com o menor número de recursos e motivos de ação. Em outras palavras, a capacidade de criar eventos trágicos a partir da mera manifestação de características da índole humana pode ser um artifício do qual apenas o gênio artístico é capaz. Quatro tragédias são destacadas por Schopenhauer nesta categoria; Clavigo de Goethe, Hamlet, Wallenstein Schiller e Cid de Corneille.

Se tomarmos como exemplo a tragédia de Hamlet a fim de testarmos a hipótese de Schopenhauer, constataremos que, de fato, todo desfecho trágico se dá por razões diretamente ligadas às características humanas como a ambição, o desejo de vingança, a loucura, a hipocrisia social e a fragilidade da mente humana em compreender o comportamento próprio e alheio. A estrutura e a própria essência da peça não invoca uma injustiça primordial um grande erro que não estaria previsto no próprio comportamento humano. Não há, também, a intervenção de uma divindade no sentido de causar uma punição por uma hybris provocada pelos homens. Apesar de haver na peça uma interferência sobrenatural, o aparecimento do fantasma do pai de Hamlet, este não determina necessariamente os atos dos personagens, o desenrolar da ação dramática se dá fundamentalmente baseada nas reações que temos cotidianamente diante dos estímulos factuais. Em Othelo, de 
Shakespeare, temos, também, o desfecho trágico como fruto da maquinação de mentes cruéis e doentias, tramas humanos, sem a interferência de um elemento sobrenatural ou extraordinário que instaure uma grande injustiça ou um acaso cego.

É preciso deixar claro, no entanto, neste contexto de crítica no qual o recurso literário da justiça poética é o alvo central, que ele não tem como finalidade introduzir um final feliz nas obras. Esta peripécia literária, obviamente, entraria em direta contradição com a própria classificação literária de tragédia e representaria em si mesma um contrassenso. O que o recurso pretende introduzir são algumas compensações de cunho moral que, mesmo não alterando o teor trágico do desfecho (morte, resignação, negação da vontade) indicaria alguma orientação ética. O problema central examinado aqui seria, então, a contraposição desta "compensação ética" com a concepção metafísica schopenhaueriana fundamentada na ideia de que a existência, enquanto sofrer, seria uma expiação da culpa original dos homens.

\begin{abstract}
Nas duas primeiras técnicas de elaboração de tragédias vemos o destino monstruoso e a maldade atroz que, no entanto, ameaçam só de longe, por conseguinte temos a esperança de nos subtrair a eles sem a necessidade de nos refugiarmos na renúncia; os contrário, na última técnica as potências que destroem a felicidade e a vida aparecem de tal forma, que vemos o grande sofrimento ser produzido por complicações cujo essencial também pode tocar 0 nosso destino, ou por ações que talvez nós mesmos seríamos capazes de realizar, e portanto não teríamos o direito de denunciar a injustiça ${ }^{9}$.
\end{abstract}

Se a injustiça que acomete o herói fosse uma injustiça originada na própria ação dramática, isto é, se surgisse no decorrer e por culpa das ações humanas, por exemplo, se o herói fosse injustamente privado de liberdade, se fosse condenado sem cometer um crime ou sem transgredir alguma lei, a justiça poética até faria sentido em certas estórias mesmo entrando em conflito com a noção mais ampla de tragédia como representação de uma infelicidade humana. Porém, quando a injustiça é atemporal, se ela não decorreu ou não se originou no tempo, na própria ação dramática, a justiça poética não cabe de forma alguma, não pode ser legítima. A culpa, neste caso, remete a uma falta essencial, esta falta reclama uma justiça e a 
única justiça que se efetiva neste sentido é o sofrimento do herói. Nas lições sobre a Metafísica do Belo Schopenhauer esclarece este aspecto:

Portanto, em conformidade com a visão apresentada, a tragédia tem a tendência de indicar ao espectador, mediante a exposição do lado terrível da vida e com a descrição de grandes infelicidades, a resignação, a renuncia, a negação da vontade de vida, para cujo fim a própria exposição apenas aponta, o espírito do espectador direcionando-se para este fim por meio da impressão que recebe, ou também permite de imediato ao herói atingir tal objetivo, expondo-o como transformado pela resignação completa e, por consequência, a maior parte das vezes recebendo bravamente a morte como salvação. Assim, a tendência da tragédia é indicar a negação da vontade de vida ${ }^{10}$.

Trata-se de uma culpa anterior às ações humanas. A tragédia, portanto, em última instância, não trata da ação sequencial propriamente dita, do desenrolar da trama e de seu nexo causal mais óbvio. A função da tragédia como expressão artística da vida está ligada a uma base metafísica mais profunda. Se retomarmos o texto do parágrafo 51 de 0 mundo como vontade e representação, veremos que, para Schopenhauer, "o sentido verdadeiro da tragédia reside na profunda intelecção de que os heróis não expiam os seus pecados individuais, mas o pecado original, isto é, a culpa da existência mesma"11.

\section{Considerações finais}

A título de conclusão, podemos afirmar, com base nesta esclarecedora citação de Schopenhauer, que é na perspectiva ética que veremos a verdadeira função da tragédia. Assim, na perspectiva estética de Schopenhauer, temos a arte a serviço da verdadeira visão pessimista do mundo. A função da arte, sobretudo da tragédia, seria revelar o fundo metafísico do mundo e da existência humana, a saber, uma concepção na qual o vir-a-ser e com ele nossa existência, são concebidos como um erro primordial. O herói trágico é aquele que do alto de sua nobreza contempla a ideia, o significado da vida, e resignando-se, isto é, negando a vontade, faz retornar, por um momento, uma atenuação da contradição ontológica trágica representada pelo dissentimento essencial do mundo consigo mesmo. A

10 SCHOPENHAUER, A. MB, cap. 16, p. 226.

11 SCHOPENHAUER, A. MVR I, § 51, p. 334. 
tragédia em seu significado artístico essencial não tem compromissos com uma "Justiça poética" ou com a compensação estética de atos morais, muito menos com um esclarecimento moral. O que se conclui, a partir das análises e classificações de Schopenhauer sobre a estrutura e sobre os efeitos das obras trágicas, é que a significação mais profunda da tragédia não está ligada a uma justificação da vida e das virtudes humanas, antes, tal significação estaria ligada diretamente a uma doutrina da resignação.

\section{Referências bibliográficas}

SCHOPENHAUER, A. O mundo como vontade e como representação. Tomo I. Trad. Jair Barboza. São Paulo: Editora Unesp, 2005.

. O mundo como vontade e como representação. Tomo II. Trad. Jair Barboza. São Paulo: Editora Unesp, 2015. Metafísica do Belo. Trad. Jair Barboza. São Paulo: Editora Unesp, 2003.

BERNUCCI, L. Justiça poética na épica latino americana moderna. Revista USP, São Paulo, no 50, pp. 238-246, junho/agosto, 2001.

NUSSBAUM, M. C. Poetic Justice: The Literary Imagination and Public Life. Beacon Press, 1995.

Recebido: 08/12/15

Received: 12/08/15

Aprovado: $19 / 12 / 15$

Approved: 12/19/15

A tragédia como gênero literário e a negação da "justiça poética" no terceiro livro de O mundo como vontade e representação, de Schopenhauer 